doi:10.1093/bjc/azh023

BRIT. J. CRIMINOL. (2004) 44, 520-532

Advance Access publication 8 April 2004

\title{
THE IMPACT OF DIFFERENT FAMILY CONFIGURATIONS ON DELINQUENCY
}

\author{
Henriette Haas*, David P. Farrington ${ }^{\dagger}$, Martin Killias $^{\ddagger}$ \\ and GHaZALa SATTAR ${ }^{\S}$
}

How do outcomes of boys who had experienced family disruption before age 12 years compare with those from intact families? This paper is based on a sample of 21,314 Swiss male recruits who completed a cross-sectional survey at age 20 years. As in the Cambridge Study, disrupted families predicted offending. However, intact high-conflict families predicted the same prevalence of offending as disrupted families. Boys not living with their mother, especially when they had lived in institutions before age 12 years, were most likely to become persistent offenders. Therefore, the dichotomy of disrupted versus intact family hides many important sub-groups, including those living with their mother (low-risk) and those who had experienced institutional rearing (high-risk).

\section{Background}

Many family factors have been shown to predict offending, including factors relating to child-rearing practices (e.g. harsh discipline, poor supervision and low parental involvement with the child) and factors relating to family characteristics (e.g. broken homes, parental conflict and family criminality) (see Farrington 2002). This paper focuses on family disruption which 'seems to be as strong a predictor of self-reported and official delinquency as other major risk factors such as low family income, large family size, poor child-rearing, poor parental supervision, low IQ, low attainment and hyperactivity' (Juby and Farrington 2001: 23). Interest in researching the link between disrupted families and delinquency has grown since the 1960s, largely because of the rise in both disrupted families and delinquency rates in Western industrialized countries.

Rodgers and Pryor (1998) renewed research on disrupted families and estimated that the risk of delinquency for children from broken homes was double that for children from intact homes. In the Newcastle Thousand Family Study (UK), Kolvin, Miller, Fleeting and Kolvin (1988) found that 53 per cent of the boys from families where the parents had separated or divorced before age five years were convicted up to age 32 years, compared with 28 per cent of the other boys. However, research shows that the relationship between family disruption and delinquency is a complex one. In the CambridgeSomerville Youth Study in Boston (US), McCord (1982) examined serious offending among 232 adolescents from broken homes due to loss of the natural father, taking into account the level of parental conflict and whether or not the mother was loving.

\footnotetext{
* Assistant professor of Forensic Psychology and Criminology, University of Lausanne, Switzerland.

${ }^{\dagger}$ Professor of Psychological Criminology, Cambridge University, UK.

${ }^{\ddagger}$ Professor of Criminology and Criminal Law, University of Lausanne, Switzerland.

${ }^{\S}$ PhD (Psychology), Home Office Research, Development and Statistics Directorate.

Corresponding address: Prof. Henriette Haas, Institut de police scientifique et de criminologie, Bâtiment de Chimie, Université de Lausanne, CH-1015 Lausanne, Switzerland. Tel. 0041216924641 (office), 0041792260661 (private); Fax 0041216924605 ; Email: henriette.hass@esc.unil.ch
} 
She found a high prevalence of delinquency among boys from broken homes without a loving mother (62 per cent) and boys from intact homes with parental conflict (52 per cent). The prevalence of offending was low for boys from an intact home with no parental conflict (26 per cent) and also for boys from a broken home with a loving mother (22 per cent), thus suggesting that coming from a broken home is less of a predictor of delinquency than the level of parental conflict (preceding the break-up of the home). It seems that the mother could compensate for the loss of the father, so long as she was loving towards her child.

Studies have examined how factors, such as age, sex and race, influence the relationship between broken homes and delinquency, but many of the conclusions are ambiguous. Some studies have found that separation at particular times in children's lives have more or less impact on delinquency. For example, Wadsworth (1979) concluded that family disruption at age 0-4 years was a stronger predictor of later delinquency than disruption at age 11-15 years. However, the Cambridge Study in Delinquent Development investigated the age of separation and found that being separated before age ten years was a predictor of delinquency, but being separated before age five years did not appear to be especially related to a delinquent outcome (West and Farrington 1973). Wells and Rankin's (1991) meta-analysis showed that the prevalence of delinquency was 10-15 per cent higher among children from broken homes than among children from intact homes. Furthermore, this relationship was stronger for less serious status offences (under-age drinking, truancy and running away from home) than for more serious index offences (burglary, theft, robbery and assault). However, no consistent results emerged with regard to the sex or race of the child or the age at time of break-up of the family.

Some studies have examined the reason for the broken home. In an English National Longitudinal Survey of over 5,000 children born in one week in 1946, Wadsworth (1979) discovered that boys from homes broken by divorce were more likely to become delinquent in adolescence than boys from intact homes and also boys from homes broken by death. Remarriage of the remaining parent was associated with an increased risk of delinquency, thus suggesting that step-parents can have a detrimental impact on their stepchildren (Farrington 1996). Criminologists have tended to use dichotomous variables (comparing two-parent to one-parent homes) to examine the link between family disruption and delinquency; however, this has been criticized by Juby and Farrington in a recent analysis of the Cambridge Study data (2001: 23):

A dichotomous variable (broken vs. intact; two-parent vs. lone-parent) ignores many important predisruption (e.g. reasons for disruption, timing of disruption, gender of the lost parent, level of conflict) and post-disruption (e.g. gender of the custodial parent, subsequent family reconstitution) characteristics of complex family disruption processes. As a result, families with very different experiences, many of which may perhaps cancel out in statistical analyses, are classified together.

\section{The Cambridge Study of London Boys}

In the Cambridge Study, family disruption had previously been measured according to temporary and permanent separations of boys from their parents (usually from the father), lasting more than one month, before their tenth birthday. West and 
Farrington (1973) found that 20 per cent of boys separated because of death or hospitalization were convicted as juveniles, compared with 32 per cent of boys separated for other reasons (mainly parental disharmony) and 16 per cent of boys from intact families. These results suggested that separation caused by death or hospitalization was not 'particularly criminogenic'. Although most analyses of family disruption concerned temporary separations, West and Farrington also examined the link between broken homes up to age 15 years and juvenile convictions. They reported that 21 per cent of boys from broken homes due to parental death were convicted as juveniles, compared with 38 per cent of boys from homes broken for other reasons, and 18 per cent of boys from intact homes.

Juby and Farrington (2001) investigated family disruption in greater detail than in previous studies. Three measures of offending were used: juvenile convictions (age 10-16 years); adult convictions (age 17-40 years) but excluding those convicted as juveniles; and juvenile self-reported delinquency (age 14 years). When permanently disrupted families (boy separated from a biological parent) versus intact families were examined, it was found that 29 per cent of boys from disrupted families were convicted as juveniles, compared with 18 per cent of boys from intact families. Odds ratios (see later) confirmed that family disruption was a significant predictor of delinquency. Juby and Farrington also examined low and high levels of conflict in intact families, concluding that family conflict in intact families was also a predictor of delinquency. In addition, delinquency rates for disrupted families and intact but conflict-ridden families were found to be similar. Other findings included:

- the loss of a mother was more damaging than the loss of a father;

- families disrupted by parental disharmony were more criminogenic than families disrupted by parental death, but which parent died was more important than whether the cause of the disruption was death or disharmony;

- delinquency rates were highest for disruptions at ages 0-4 and 10-14 years and lowest for disruptions at age 5-9 years.

In the period after family disruption, it was found that the prevalence of delinquency increased with the number of parental transitions, i.e. changes of the operative parents. The prevalence of offending was lower for boys who lived continuously with their mother after the disruption than for boys who lived with their fathers or other relatives. Most interestingly, the prevalence of offending was the same for boys from disrupted families who lived with their mother as for boys in intact harmonious families.

Life-course theories consider the period before and after separation to be important to the development of later delinquency. The more disruptive incidents a child experiences, the more damaging the outcome (e.g. delinquency). Also important is the timing of life-course transitions and the number of parental transitions during the post-separation period. In comparison, trauma theories (e.g. Bowlby's 1951 trauma theory and Hirschi's 1969 control theory) focus on parental loss and weakening of the attachment between child and parent. These theories suggest that, for children to grow into mentally healthy adults, they would need to have had a relationship with their mother that was loving, warm, stable and continuous. Finally, selection theories argue that the association between disrupted families and delinquency is due to pre-existing differences in factors such as parental conflict, which can affect child-rearing practices. According to 
these theories, parental conflict is more of an influencing factor than family structure in predicting later delinquency. Juby and Farrington (2001: 36) concluded that:

These results confirm that disrupted families in general are associated with relatively high delinquency rates. However, they also show the need for sophisticated analysis of different kinds of family configurations. Our results are limited by small numbers (only 75 boys from disrupted families). Nevertheless, they suggest that life course theories are more plausible than trauma or selection theories in explaining the link between disrupted families and delinquency.

\section{The Swiss Study}

Many of the longitudinal criminological studies advancing our understanding of offending, including possible causal relationships between life events and later outcomes, have been conducted in the UK and the US. Similar studies have rarely been carried out in continental Europe, for a number of reasons. In particular, there exist rigid data-protection laws, which guarantee participants full anonymity, but prohibit researchers from tracing participants on repeat occasions. Also, the time, of several years and even decades, that has to elapse before final results are available makes it difficult for researchers to secure the long-term funding necessary to conduct prospective longitudinal studies. However, European criminologists have contributed to the debate on the link between family disruption and delinquency, by conducting cross-sectional studies with large samples. A limitation of longitudinal studies is that they can rarely be conducted with large samples. Using large samples means that even relatively rare events are likely to occur in sufficient numbers for the use of statistical analysis.

This paper describes such a large-scale cross-sectional study, of more than 20,000 males in Switzerland. Recruits to the Swiss Army are surveyed every year on a particular topic of relevance to social policy. Switzerland has general conscription and the final sample was about 70 per cent of the total cohort of 20 -year-old Swiss males in 1997. As the recruiting process implies a certain selection, this sample is cut off at both ends of the extremes: the most obviously deviant men and also a disproportionate number of university students are not enrolled in the army. However, given the large size of the sample, it still contains a large number of delinquent men, especially as a previous criminal record is not a reason for exclusion from the army according to Swiss law. In 1997, recruits were interviewed on the topic of delinquency and violence. After approximately four weeks of basic military training, male recruits completed a questionnaire of about 900 items, which included details of the sociodemographic circumstances of their childhood and adolescence (including delinquency, mental health issues and deviant behaviour). The questionnaires were normally completed in groups of 35-60, with recruits seated spaced out from one another and supervised by civilian staff. The recruits were guaranteed complete anonymity and were assured that their responses would remain confidential.

Completed questionnaires were dropped in a type of 'ballot box'; this approach ensured a low refusal rate. Participation in the survey was mandatory. Recruits were encouraged to complete all items, although they were able to skip questions. As a result, more than 94 per cent of recruits answered both the delinquency and the victimization questions and an average of only about 5 per cent of all questions remained unanswered. The content of the questionnaires was examined and those considered to 
lack credibility (e.g. they contained extreme and/or unrealistic reporting of delinquency and violence) were excluded. The final number of questionnaires that were analysed was 21,314. Men of the same age group who did not serve in the army in 1997 were invited to answer by mail a short version of the questionnaire. This second sample showed a bimodal distribution, with a disproportionate number of university students. Illegal drug use and sexual harassment were admitted somewhat more often by the men not enrolled in the army, whereas physical violence and forced sexual intercourse were admitted more by army recruits. However, the differences were not large (Haas 2001).

The aim of the present study was to build on the work of Juby and Farrington (2001), by using a similar model, to look in greater detail at the offending of men who grew up in families affected by different types of disruption. In the Cambridge Study, data were collected on 75 boys who grew up in disrupted families. The group found to be the most problematic in terms of delinquency were boys who had grown up without a mother; however, this group contained only 36 participants. The Swiss Study was able to collect data on considerably more participants who had grown up in disrupted families ( $n=2,573$ vs 18,260 from intact families vs 481 missing), thus making it possible to examine in detail the following four mutually exclusive groups:

(1) 1,510 males from a disrupted family, who have lived continuously with their mother (although not necessarily all the time with their father), before age 12 years;

(2) 140 males from a disrupted family, who have lived continuously with their father (although not necessarily all the time with their mother), before age 12 years;

(3) 752 males who had lived with a foster family or with relatives for more than one year, before age 12 years;

(4) 171 males who had lived in an institution (mostly children's homes but, in rare cases, mainstream hospitals or orphanages) for at least one year, before age 12 years.

Having a large sample made it possible to further disentangle and examine the impact of different family configurations on delinquency. For example, it was possible to look at family configurations that are rare in contemporary society (e.g. paternal custody of children) and also at rare events (e.g. children who have spent time living in institutions).

\section{Results Concerning the Comparison of Swiss and London Data}

It was found that 12.1 per cent of Swiss subjects suffered from the absence of one of the parents before age 12 years, compared with 85.7 per cent of males who reported living in an intact family until (at least) age 11 years; this was unknown for 2.3 per cent of respondents. Comparisons were also made between high-conflict families $(n=3,063)$, low-conflict families $(n=15,197)$ and disrupted families $(n=2,573)$. However, the definition of high-conflict was different from that used in the Cambridge Study. In the Cambridge Study, high conflict in a family was defined as 'chronic tension or disagreement in many fields between the operative parents' (Juby and Farrington 2001: 30). High conflict did not necessarily include spouse battering or heavy drinking by either parent, and therefore was essentially measuring the psychological climate in the family.

In the Swiss Study, there was considered to be high conflict in a family when there was tension and a lack of affection between the parents. The information for the 
composite variable on the parents' relationship was based on only a few items and, for that reason, the variable on spouse battering was added, in order to include more conflict-ridden families. Using this working definition, 71.3 per cent of the recruits reported having an intact family with few conflicts, while 14.4 per cent reported experiencing a high level of tension, signs of an absence of affection, or spousal violence in their intact families. This composite variable of the psychological climate in the families is a rather subjective variable. It was therefore expected that the findings of the two studies might differ.

In the Swiss Study (see also Haas 2001), self-reported juvenile delinquency was measured by using a composite variable, which approximated to the definition of conduct disorder used in DSM-IV (APA 1994), whereas the Cambridge Study used a total of 38 items to measure juvenile delinquency (see West and Farrington 1973). Although the two studies used different measures of juvenile delinquency, the results were found to be reasonably similar in regard to the comparison of intact and disrupted families, thus underlining the comparability of the results. In order to make comparisons with the London data (Juby and Farrington 2001), odds ratios (ORs) were calculated. ORs measure the strength of effect and, generally speaking, an OR of 2 or more is considered to indicate a strong effect (Cohen 1966).

Table 1 presents ORs relating different family configurations to juvenile delinquency and court appearances. The Swiss data replicated the Cambridge Study in showing that boys from disrupted families were more likely to become delinquents, with similar odds ratios, than those from intact families. Similarly, in both studies, male children from intact high-conflict families were more likely to become delinquents than those from intact low-conflict families. Also, both studies showed that boys from disrupted families were hardly more likely to become delinquents than those from intact high-conflict families and that boys from disrupted families living with their mother were less delinquent than those who were not living with their mother. Another result reproduced in both studies was that boys from disrupted families not living with their mother were more delinquent than those from intact low-conflict families or intact high-conflict families. And, finally, in both studies, results obtained with self-reported delinquency were similar to results obtained with court appearances.

TABLE 1 Odds ratios relating different family configurations to juvenile delinquency and court appearances

\begin{tabular}{|c|c|c|c|c|}
\hline \multirow[t]{2}{*}{ Family configuration } & \multicolumn{2}{|c|}{$\begin{array}{c}\text { Self-reported juvenile } \\
\text { delinquency }\end{array}$} & \multicolumn{2}{|c|}{$\begin{array}{l}\text { Appearances before } \\
\text { juvenile court }\end{array}$} \\
\hline & Swiss & Cambridge & Swiss & Cambridge \\
\hline Intact/disrupted families & $2.2 * *$ & $2.1^{*}$ & $1.8 * *$ & $1.9 *$ \\
\hline Intact low-conflict/intact high-conflict & $2.0 * *$ & $2.4^{*}$ & $1.7 * *$ & $2.8^{*}$ \\
\hline Intact high-conflict/disrupted families & $1.3^{* *}$ & $1.1^{\mathrm{ns}}$ & $1.2 * *$ & $1.0^{\mathrm{ns}}$ \\
\hline Intact low-conflict/disrupted with mother & $2.1 * *$ & $1.1^{\mathrm{ns}}$ & $1.5^{* *}$ & $1.0^{\mathrm{ns}}$ \\
\hline Intact low-conflict/disrupted not with mother & $3.6^{* *}$ & $5.9 *$ & $3.0 * *$ & $6.0 *$ \\
\hline Disrupted with mother/intact high-conflict & $1.0^{\mathrm{ns}}$ & $2.2^{\mathrm{ns}}$ & $1.1^{\mathrm{ns}}$ & $2.9^{\mathrm{ns}}$ \\
\hline Intact high-conflict/disrupted not with mother & $1.8^{* *}$ & $2.5 *$ & $1.7 * *$ & $2.1^{\mathrm{ns}}$ \\
\hline Disrupted with mother/disrupted not with mother & $1.7 * *$ & $5.3^{*}$ & $1.9 * *$ & $5.9 *$ \\
\hline
\end{tabular}

$\mathrm{N}=20,833$ for Swiss Study; $\mathrm{N}=411$ for Cambridge Study.

ns, not significant; *, significant at $\mathrm{p}<0.05 ; * *$, significant at $\mathrm{p}<0.01$. 
However, there were also some differences in results between the Swiss and Cambridge Studies. In the Cambridge Study, boys living in disrupted families with their mothers were no more likely to be delinquent than boys living in intact low-conflict families, but this was not found in the Swiss Study. Also, in the Cambridge Study, boys living in intact high-conflict families were more likely to be delinquent than those from disrupted families living with their mother, but this was not found in the Swiss Study. The odds ratio being close to 1.0 indicates that Swiss boys living in disrupted families with their mother were about as delinquent as boys from intact high-conflict families.

The main finding in the two studies is certainly that high conflict in an intact family may have as much of a detrimental effect on children as divorce or separation. This result favours selection theories about the association of broken homes and delinquency over trauma theories.

\section{Impact of Specific Family Configurations on Childhood and Adolescence}

After having established the basic results of the cross-sectional retrospective data, further analyses were carried out to examine more closely the impact of rare family configurations on juvenile delinquency. Of all 21,314 Swiss recruits, 10.1 per cent had reported marked juvenile delinquency (severe conduct disorder) during their teenage years and 5.8 per cent had had to appear before a juvenile court.

Table 2 shows the impact of family configurations, including rare ones, on juvenile delinquency and court appearances. Of all respondents, 7.1 per cent had lived in a disrupted family continuously with their mother until at least age 11 years. A surprisingly large number of boys from disrupted families had been separated from their mother,

TABLE 2 Impact of family configurations on prevalence of juvenile delinquency and court appearance in the Swiss sample

\begin{tabular}{|c|c|c|}
\hline Mutually exclusive categories & $\begin{array}{l}\text { Self-reported juvenile } \\
\text { delinquency }(10.1 \%)\end{array}$ & $\begin{array}{l}\text { Appearance before } \\
\text { juvenile court }(5.9 \%)\end{array}$ \\
\hline \multicolumn{3}{|l|}{ 1. All males } \\
\hline Intact low-conflict family $(\mathrm{n}=15,197)$ & 7.6 & 4.7 \\
\hline Intact high-conflict family $(\mathrm{n}=3,063)$ & 14.0 & 7.9 \\
\hline Disrupted, living always with mother $(\mathrm{n}=1,510)$ & 14.5 & 7.1 \\
\hline Disrupted not with mother (DNWM) $(\mathrm{n}=1,063)$ & 22.9 & 12.9 \\
\hline $\mathrm{N}=21,314$, missing $=481$. Significance: & $\mathrm{p}<0.001$ & $\mathrm{p}<0.001$ \\
\hline \multicolumn{3}{|l|}{ 2. Subdivision of DNWM } \\
\hline $\begin{array}{l}\text { Disrupted, living always with the father and separated } \\
\text { from the mother for more than } 1 \text { year before age } 12 \\
\text { years }(n=140)\end{array}$ & 25.0 & 13.6 \\
\hline $\begin{array}{l}\text { Disrupted, living with foster family or relatives for more } \\
\text { than } 1 \text { year before age } 12 \text { years }(n=752)\end{array}$ & 19.8 & 10.8 \\
\hline $\begin{array}{l}\text { Disrupted, living in an institution for more than } 1 \text { year } \\
\text { before age } 12 \text { years }(n=171)\end{array}$ & 34.5 & 21.6 \\
\hline$N=1,063$. Significance: & $\mathrm{p}<0.001$ & $\mathrm{p}<0.001$ \\
\hline \multicolumn{3}{|l|}{ 3. Subdivision of institutionalization } \\
\hline $\begin{array}{l}\text { Institutionalized between ages } 6 \text { and } 11 \text { years but not } \\
\text { before age } 6 \text { years }(n=94)\end{array}$ & 39.4 & 21.3 \\
\hline Institutionalized before age 6 years but not after $(n=52)$ & 32.7 & 25.0 \\
\hline Institutionalized during both periods $(n=25)$ & 20.0 & 16.0 \\
\hline $\mathrm{N}=171$. Significance: & $\mathrm{p}<0.18(\mathrm{~ns})$ & $\mathrm{p}<0.66(\mathrm{~ns})$ \\
\hline
\end{tabular}


for at least one year, before age 12 years (41.3 per cent of all subjects from disrupted families), although some of these boys may still have lived for a reasonable period of time with their mother; for example, they may have only been separated for a long period during their mother's hospitalization. Some separations may have occurred when children were placed in the care of grandparents, while their parents emigrated to Switzerland. All the respondents were Swiss citizens, yet 18.9 per cent had at least one immigrant parent. This is because Switzerland has experienced large-scale immigration during the last few decades of the twentieth century. This fact may help explain why such a large proportion of recruits (5.0 per cent) had reported living separately from their mothers for a long period, as children. The proportion of boys with conduct disorders and juvenile court appearances was similar for boys coming from intact but high-conflict families and from disrupted families who lived with their mother. The proportions were higher for boys from disrupted families who lived with other relatives/ foster parents or their father and those who had lived in institutions $($ sig. $\mathrm{P}<0.01)$. The number of boys under permanent care of their father $(n=140)$ and not their mother after a disruption was relatively low (5.4 per cent of disrupted cases). The loss of a mother was more damaging than the loss of a father-again, a result already found in the Cambridge Study.

Table 2.3 presents data on boys who had spent at least one year in an institution. Because of the small absolute numbers, delinquency did not vary significantly with institutional categories. Most institutionalized boys did not become juvenile delinquents. This is a positive finding, although (as mentioned earlier) army recruitment involves a selection process, which is likely to have filtered out some of the most deviant men in the cohort. For that reason, our data may overestimate the prevalence of resiliency, which means the capability of individuals and systems (families, groups and communities) to cope effectively in the face of considerable adversity or risk. The word, stemming from metallurgy, meant originally the capacity of the metal to resist shock and torsion, preserving its original form (Cyrulnik 1999). Its existence has for a long time been neglected because of the predominance of clinical studies, which focus on individuals who show deviant outcomes. On the other hand, the samples of longitudinal studies in the community are often too small to contain a sufficient number of children who were exposed to severe risks. Interestingly, the most traumatized boys in the Swiss sample (those institutionalized during both periods) seemed to have become less delinquent than those who were less traumatized, but were still exposed to severe risk factors. An explanation for this finding will be offered later in the paper, when the data on the subjects' experiences during adulthood are analysed (as findings for adult delinquency and court appearances are similar).

\section{Impact of Specific Family Configurations on Adult Convictions}

In studying offending, it is important to use not only official records and self-reported data on juvenile delinquency, but also to consider later outcomes, because many children grow out of crime. Also, collecting data on later outcomes can help to reveal issues that may have been masked during childhood.

Table 3 presents the odds ratios for intact families versus non-intact families for court appearances of males during adulthood, for the Swiss and Cambridge Studies. It can be seen that the odds ratios are similar for both studies, apart from the differences 
HAAS ET AL.

TABLE 3 Odds ratios relating intact and non-intact families to adult court appearances

\begin{tabular}{llc}
\hline Family configuration & \multicolumn{2}{c}{ Appearances before adult court } \\
\cline { 2 - 3 } & Swiss & Cambridge \\
\hline Intact/disrupted families & $1.4^{* *}$ & $1.8^{\text {ns }}$ \\
Intact low-conflict/intact high-conflict & $1.3^{* *}$ & $1.3^{\text {ns }}$ \\
Intact high-conflict/disrupted families & $1.1^{\text {ns }}$ & $1.4^{\text {ns }}$ \\
Intact low-conflict/disrupted with mother & $1.0^{\text {ns }}$ & $1.1^{\text {ns }}$ \\
Intact low-conflict/disrupted not with mother & $2.2^{* *}$ & $4.1^{*}$ \\
Disrupted with mother/intact high-conflict & $1.4^{\text {ns }}$ & $1.2^{\text {ns }}$ \\
Intact high-conflict/disrupted not with mother & $1.7^{* *}$ & $3.0^{*}$ \\
Disrupted with mother/disrupted not with mother & $2.3^{* *}$ & $3.6^{*}$ \\
\hline
\end{tabular}

$\mathrm{N}=20,833$ for Swiss Study; $\mathrm{N}=411$ for Cambridge Study.

ns, not significant; *, significant at $\mathrm{p}<0.05 ; * *$, significant at $\mathrm{p}<0.01$.

between the results for those boys who lived with their mother and those who did not. Boys from disrupted families separated from their mother were worse in the Cambridge Study: the OR for the Swiss Study was 2.2 (95 per cent confidence interval ranging from 1.7 to 2.9) compared with 4.1 for the Cambridge Study. This suggests that the Swiss boys, born in the late-1970s, separated from their mother, had a relatively lower risk of appearing in court as adults than the British boys, born in the 1960s. This may be because of the changes to the structure of families in recent times. Again, compared to boys coming from intact high-conflict families, Swiss boys living in disrupted families with their mothers were more often convicted as young adults than their British peers. However, the London boys from disrupted families not living with their mother were relatively more likely than the Swiss boys to have an adult court appearance, compared with boys from intact high-conflict families.

Table 4 shows the proportion of subjects involved in delinquency during the previous 12 months (i.e. at age 19 years) by family configuration: 3.2 per cent of the 21,314 males had to appear before an adult court. Within the group of Swiss young men, roughly one-third (34.8 per cent) were considered model citizens, because they reported no delinquent behaviour at all as young adults in the questionnaire. Another third (34.6 per cent) reported some occasional acts of delinquency (such as speeding) but the offences were not considered serious enough to warrant these males being categorized as offenders; 21.3 per cent were categorized as 'average offenders' and another 8.3 per cent of respondents were 'persistent offenders' according to their self-reports. These categories were defined in statistical terms (for comprehensive explanations, see Haas 2001: 226; present definition contains slight modifications). A distinction between offenders was required because of large individual differences. Briefly, the 'average offenders' group scored above the mean for one or more of the following: (a) the number of admitted violent acts, (b) the number of sexual offences or acts of sexual harassment, (c) the number of other delinquent acts, or (d) the total number of all offences or the total number of all victims, while still being below the score qualifying for 'persistent offenders'.

The 'persistent offenders' committed more than the mean score plus two standard deviations in any one of the offences/victims domains stated above. The 8.1 per cent of respondents who met the criteria for 'persistent offenders' were responsible for 57 per cent of all offences, 67 per cent of all violent acts and 85 per cent of all sexual offences or acts of sexual harassment committed by the cohort during the 12 months before 
they entered basic military training. Thus, the existence of a hard core of delinquent young men who are responsible for a majority of all delinquent acts, and especially a large majority of serious crimes, was confirmed by a cross-sectional study based on selfreports and not on official records (cf. Loeber, Farrington and Waschbusch 1998; Wolfgang, Figlio and Sellin 1972).

The results presented in Table 4.1 support the findings from the German 30-year longitudinal study of convicted delinquent young men of the city of Tübingen and a comparison group of non-delinquents (Thomas, Stelly, Kerner and Weitekamp 1998). Minor self-reported juvenile delinquency was reported in both their groups, contrary to index offences committed during young adulthood, which were committed almost exclusively by the group of the convicted delinquent men. These authors found that there was an important difference in previous exposure to risks between those who committed minor self-reported juvenile delinquency and those who committed severe criminal acts. It seemed that risk factors were particularly influential in cases of serious offending. The present results support this, suggesting that less severe offending may be caused by other factors.

The data in Table 4.1 and 4.2 show that boys who had lived with their fathers continuously until age 12 years had a worse prognosis than boys who had lived continuously with their mother and boys who had lived in high-conflict but intact families for persistent offending and court convictions. The group most at risk of these outcomes are boys who had lived away from their family, in an institution.

Table 4.3 presents a breakdown of the data on the relatively rare group of boys who had lived in an institution. There is no question that children placed in institutions

TABLE 4 Prevalence of offending in young adulthood by family configuration in the Swiss sample

\begin{tabular}{|c|c|c|c|}
\hline Mutually exclusive categories & $\begin{array}{l}\text { Average } \\
\text { offenders } \\
(21.3 \%)\end{array}$ & $\begin{array}{l}\text { Persistent } \\
\text { offenders } \\
(8.3 \%)\end{array}$ & $\begin{array}{l}\text { Appearances } \\
\text { before adult } \\
\text { court }(3.2 \%)\end{array}$ \\
\hline \multicolumn{4}{|l|}{ 1. All males } \\
\hline Intact low-conflict family $(\mathrm{n}=15,197)$ & 20.5 & 7.0 & 2.8 \\
\hline Intact high-conflict family $(\mathrm{n}=3,063)$ & 24.3 & 9.5 & 3.7 \\
\hline Disrupted, living always with mother $(\mathrm{n}=1,510)$ & 23.3 & 10.9 & 2.8 \\
\hline Disrupted not with mother $(\mathrm{DNWM})(\mathrm{n}=1,063)$ & 20.6 & 17.3 & 6.1 \\
\hline $\mathrm{N}=21,314$, missing $=481$. Significance: & $\mathrm{p}<0.001$ & $\mathrm{p}<0.001$ & $\mathrm{p}<0.001$ \\
\hline \multicolumn{4}{|l|}{ 2. Subdivision of DNWM } \\
\hline $\begin{array}{l}\text { Disrupted, living always with the father and separated } \\
\text { from the mother for more than } 1 \text { year before age } \\
12 \text { years }(n=140)\end{array}$ & 23.6 & 16.4 & 4.3 \\
\hline $\begin{array}{l}\text { Disrupted, living with foster family or relatives for } \\
\text { more than } 1 \text { year before age } 12 \text { years }(n=752)\end{array}$ & 19.4 & 16.2 & 5.6 \\
\hline $\begin{array}{l}\text { Disrupted, living in an institution for more than } \\
1 \text { year before age } 12 \text { years }(n=171)\end{array}$ & 23.4 & 22.8 & 9.9 \\
\hline $\mathrm{N}=1,063$. Significance: & $\begin{array}{l}\mathrm{p}<0.15 \\
(\mathrm{~ns})\end{array}$ & $\begin{array}{l}\mathrm{p}<0.12 \\
(\mathrm{~ns})\end{array}$ & $\mathrm{p}<0.06(\mathrm{~ns})$ \\
\hline \multicolumn{4}{|l|}{ 3. Subdivision of institutionalization } \\
\hline $\begin{array}{l}\text { Institutionalized between ages } 6 \text { and } 11 \text { years } \\
\quad(n=94) \text {, not before }\end{array}$ & 30.9 & 20.2 & 9.6 \\
\hline Institutionalized before age 6 years $(n=52)$, not after & 15.4 & 26.9 & 15.4 \\
\hline Institutionalized both periods $(n=25)$ & 12.0 & 24.0 & 0.0 \\
\hline $\mathrm{N}=171$. Significance: & $\mathrm{p}<0.05$ & $\begin{array}{l}\mathrm{p}<0.64 \\
(\mathrm{~ns})\end{array}$ & $\mathrm{p}<0.11(\mathrm{~ns})$ \\
\hline
\end{tabular}


often suffer from long-term consequences, because of either the absence of a sufficiently warm and firm family or a surplus of risk factors. Boys who had lived in an institution for more than one year before age 12 years were found to be the most deviant group (Table 4.3). However, it would be jumping to conclusions to attribute this result solely to a negative influence of institutions and not to the correlated risk factors in such cases. In fact, we have evidence that well managed homes can have a therapeutic effect, because the placement in an institution of adolescents at risk turned out to be a protective factor against adult violence in a logistic regression analysis of 33 different factors (Haas 2001: 197).

Surprisingly, the boys who had been institutionalized in both time periods (before age 6 years and between ages 6 and 11 years) were least likely to have adult court appearances and to be average offenders. Note that not all boys at risk had the delinquent outcome!

\section{Summary and Conclusion}

The cross-sectional study of 21,314 Swiss army recruits provided an opportunity for an in-depth analysis of the consequences of different family constellations on adult behaviour and disturbances. Overall, our data suggest that there is a link between disrupted families and delinquency, but that many important pre-disruption variables such as a conflict-ridden family climate may be masked behind this variable. Overt marital conflict may be greatly distressing to children and we cannot exclude that the stress may be reduced when the partners finally separate from one another. There needs to be investigation of the links in the causal chain between disrupted families and outcomes. This result supports previous analyses of the Cambridge Study data by Juby and Farrington (2001).

Overall, the research suggests there is a link between broken homes and delinquency, but that the detrimental impact of a family break-up can be lessened if the remaining parent, normally the mother, is warm and loving. In a second step, we compared boys from disrupted families who had been living constantly with their mother with those who had been living constantly with their father, and with those who had been living with relatives or a foster family and, finally, with those who lived in an institution for more than one year of their life before the age of 11 years. As in the Cambridge data, the loss of the mother proved to be more damaging than the loss of the father. We have also seen that the extended family (such as grandparents) or foster families who become more involved in a boy's life can provide additional nurturing resources.

Additional information is needed on those children who thrive despite prolonged placement outside the family (which is often combined with other adverse, potentially traumatic circumstances in their life). Therefore, it is important to focus research on the potential for resilience among these children. Some research on the repercussions of conflict and family disruption suggests that academic and social competence and structured school environments can be protective factors, promoting resilience in adolescents who experience family transitions (Hetherington 1993). One male who has apparently had a very difficult family history has written the following note among the commentaries for which we left space at the end of the questionnaire:

I've had a difficult childhood. My parents were divorced when I was 5 years old. My father was an alcoholic and has abused my sister. This had been very difficult for me. Then, during the next 5 years I was 
THE IMPACT OF DIFFERENT FAMILY CONFIGURATIONS ON DELINQUENCY

placed in an orphanage, then in two foster families. With the first family it didn't work out well, but the second one has completely changed my life. I think a child growing up in an unfavourable environment has still got a fair chance to free himself. If he has a good character, he will develop better in a new family. Concerning my own parents, I have never wanted to do what they did. I don't drink and I would never want to do harm to a child.

From these analyses and those of the Cambridge Study, it is clear that the simple dichotomy of disrupted or intact family includes many important sub-groups, including those living with their mother and those who had experienced institutional rearing.

\section{REFERENCES}

American Psychiatric Association (APA) (eds) (1994), Diagnostic and Statistical Manual of Mental Disorders DSM-IV. 4th Edition. Washington, DC.

Bowlby, J. (1951), Maternal Care and Mental Health. Geneva: World Health Organisation.

Cohen, P. (1996), 'Childhood Risks for Young Adult Symptoms of Personality Disorder: Method and Substance', Multivariate Behavioral Research, 31: 121-48.

Cyrulnik, B. (1999), Un Merveilleux Malheur. Paris: O. Jacob.

Farrington, D. P., Barnes, G. and Lambert, S. (1996), 'The Concentration of Offending in Families', Legal and Criminological Psychology, 1: 47-63.

Farrington, D. P. (2002), 'Families and Crime', in J. Q. Wilson and J. Petersilia, eds, Crime: Public Policies for Crime Control. 2nd Edition. Oakland, California: Institute for Contemporary Studies Press. pp. 129-48.

HaAs, H. S. (2001), Agressions et Victimisation: Une Enquête sur les Délinquants Violents et Sexuels non Détectés. Aarau, Switzerland: Editions Sauerlaender. ISBN 3-7941-4915-7. (English translation: Violence and Victimization. A Study on Violent and Sex Offenders Unknown to the Police).

Hetherington, E. M. (1993), 'An Overview of the Virginia Longitudinal Study of Divorce and Remarriage with a Focus on Early Adolescence', Journal of Family Psychology, 7: 39-56.

Hirschi, T. (1996), Causes of Delinquency. Berkeley: University of California Press.

Juby, H. and Farrington, D. P. (2001), 'Disentangling the Link between Disrupted Families and Delinquency', British Journal of Criminology, 41: 22-40.

Kolvin, I., Miller, F. J., Fleeting, M. and Kolvin, A. (1988), 'Social and Parenting Factors Affecting Criminal Offence Rates: Findings from Newcastle Thousand Family Study (1947-80)', British Journal of Psychiatry, 152: 80-90.

Loeber, R., Farrington, D. P. and Waschbusch, D. A. (1998), 'Serious and Violent Juvenile Offenders', in R. Loeber and D. P. Farrington, eds, Serious and Violent Juvenile Offenders. London: Sage Publications. pp. 13-29.

Mccord, J. (1982), 'A longitudinal View of the Relationship between Paternal Absence and Crime', in J. Gunn and D. P. Farrington, eds, Abnormal Offenders, Delinquency, and the Criminal Justice System. Chichester: Wiley. pp. 113-28.

Robins, L. N. (1966), Deviant Children Grown Up: A Sociological and Psychiatric Study of Sociopathic Personality. Baltimore: Williams and Wilkins.

Rodgers, B. and Pryor, J. (1998), Divorce and Separation: The Outcomes for Children. York: Joseph Rowntree Foundation.

Thomas, J., Stelly, W., Kerner, H.-J. and Weitekamp, E. (1998), 'Kontinuität und Diskontinuität sozialer Auffälligkeiten im Lebenslauf', Monatsschrift für Kriminologie und Strafrechtsreform, 81: 104-22. 
Wadsworth, M. (1979), Roots of Delinquency: Infancy, Adolescence and Crime. Oxford: Martin Robertson.

Wells, L. E. and Rankin, J. H. (1991), 'Families and Delinquency: A Meta-analysis of the Impact of Broken Homes', Social Problems, 38: 71-93.

West, D. and Farrington, D. P. (1973), Who Becomes Delinquent? London: Heinemann.

West, D. and Farrington, D. P. (1977), The Delinquent Way of Life. London: Heinemann.

Wolfgang, M., Figlio, R. and Sellin, T. (1972), Delinquency in a Birth Cohort. Chicago: University of Chicago Press. 